\title{
Altered blood gene expression of tumor-related genes (PRKCB, BECN1 and CDKN2A) in
}

\section{Alzheimer's disease}

Anna Antonell ${ }^{1}$, Albert Lladó ${ }^{1}$, Raquel Sánchez-Valle ${ }^{1}$, Coral Sanfeliu ${ }^{2}$, Teresa Casserras ${ }^{3}$, Lorena Rami ${ }^{1}$, Cristina Muñoz-García ${ }^{1}$, Adrià Dangla-Valls ${ }^{1}$, Mircea Balasa ${ }^{1}$, Patricia Boya ${ }^{4}$, Susana G Kalko ${ }^{3}$, José Luis Molinuevo'.

\author{
${ }^{1}$ Alzheimer's disease and other cognitive disorders unit. Neurology Service. Hospital Clínic, Institut \\ d'Investigacions BiomèdiquesAugust Pi i Sunyer (IDIBAPS), Barcelona, Spain \\ ${ }^{2}$ Department of Brain Ischemia and Neurodegeneration, Institut d'Investigacions Biomèdiques de \\ Barcelona (IIBB)-Consejo Superior de Investigaciones Científicas (CSIC), Barcelona, Spain \\ ${ }^{3}$ Bioinformatics Core Facility, IDIBAPS - CEK, Hospital Clínic/Universitat de Barcelona, Barcelona, \\ Spain \\ ${ }^{4}$ Department of Cellular and Molecular Biology, Centro de Investigaciones Biológicas. (CIB), Consejo \\ Superior de Investigaciones Científicas (CSIC), Madrid, Spain

\section{Corresponding author:}

Anna Antonell, $\mathrm{PhD}$

Alzheimer's Disease and Other Cognitive Disorders Unit

Center for Biomedical Research CELLEX (CRBC)

Planta 3, sector B

C/Casanova, 143

08036, Barcelona, Spain

Phone. +34-932275400 (ext.4814)

antonell@clinic.ub.es

Keywords: Gene expression; blood; Alzheimer's disease; preclinical; autophagy; mitochondria

\section{Acknowledgments}

This study was supported by grants to JLM (Consolider CSD2010-00045) and to ALL (PI14/00282, ISCIII, Cofinancia FEDER, Unión Europea, Otra manera de hacer Europa) from the Spanish Ministry of Economy and Competitiveness. The research leading to these results has received support from the Innovative Medicines Initiative Joint Undertaking under grant agreement $n^{\circ} 115568$, resources of which are composed of financial contribution from the European Union's Seventh Framework Programme (FP7/2007-2013) and EFPIA companies' in kind contribution. The authors are grateful to Alicia Mansilla for excellent technical assistance. This work was developed at the Centre de Recerca Biomèdica Cellex, Barcelona, Spain. 


\begin{abstract}
Alzheimer's disease (AD) is the most common of the neurodegenerative diseases. Recent diagnostic criteria have defined a preclinical disease phase during which neuropathological substrates are thought to be present in the brain. There is an urgent need to find measurable alterations in this phase as well as a good peripheral biomarker in the blood. We selected a cohort of 100 subjects (controls = 47; preclinical $\mathrm{AD}=11$; patients with $\mathrm{AD}=42$ ) and analyzed whole blood expression of 20 genes by quantitative polymerase chain reaction. The selected genes belonged to calcium-signaling, senescence and autophagy, and mitochondria/oxidative stress pathways. Additionally, two genes associated with an increased risk of developing $\mathrm{AD}(C L U$ and $B I N 1)$ were also analyzed. We detected significantly different gene expressions of $B E C N 1$ and PRKCB between the control and the AD groups; and, of CDKN2A between the control and the preclinical AD groups. Notably, these three genes are also considered tumor suppressor (CDKN2A and $B E C N 1)$ or tumor promoter $(P R K C B)$ genes. Gene-gene expression Pearson correlations were computed separately for controls and patients with AD. The significant correlations $(\mathrm{p}<0.001)$ were represented in a network analysis with Cytoscape tool, which suggested an uncoupling of mitochondriarelated genes in $\mathrm{AD}$ group. Whole blood is emerging as a valuable tissue in the study of the physiopathology of AD.
\end{abstract}




\section{Introduction}

Alzheimer's disease (AD) is the most common of the neurodegenerative diseases. It is characterized by an initial alteration of episodic memory that progresses to dementia in later stages. Most patients with AD are sporadic, with evidence of a complex multifactorial etiology in which genetic and environmental factors contribute to the disease development. Many genome-wide association studies have tried to link the risk of suffering $\mathrm{AD}$ with certain genes. Consequently, we know that the apolipoprotein $\mathrm{E}(A P O E)$ gene (specifically the $\varepsilon 4$ allele) has an important role, with other important susceptibility loci being the clusterin $(C L U)$ and bridging integrator 1 (BIN1) genes. Indeed, single-nucleotide polymorphisms in these genes are associated with increased risk of developing $\mathrm{AD}$ (http://www.alzgene.org/).

In $\mathrm{AD}$, the underlying neuropathological findings are the extracellular deposition of $\beta$-amyloid (A $\beta$ ) peptide plaques, intracellular neurofibrillary tangles (consisting of hyperphosphorylated aggregates of the microtubule-associated protein tau) and selective neuronal loss [1]. Thus, biomarkers of brain amyloid deposition, such as the reduction of $\mathrm{A} \beta 42$ in cerebrospinal fluid (CSF) or increased tracer retention on amyloid positron emission tomography (PET) have been described as early biochemical hallmarks of the disease. Other CSF biomarkers, such as increased levels of total tau protein (t-tau) and phosphorylated tau at threonine 181 (p-tau), are altered later in the progression of the disease and indicate neuronal injury [2].

Recent consensus criteria [3] have defined the preclinical stage of AD (Pre-AD) as patients with normal cognition, but abnormal amyloid biomarkers. Nevertheless, although such patients can be defined as Pre$\mathrm{AD}$, this does not mean that all of them will develop the clinical symptoms of the disease, nor can it predict when it might happen. In that sense, diagnosis of AD cannot be established in the Pre-AD stage, even though such patients are part of both observational research studies and clinical trials aiming to prevent or delay disease onset.

Several studies have tried to identify a gene expression signature in the peripheral blood that has diagnostic value for the detection of $\mathrm{AD}$ [4-8]. Although the validity of the blood transcriptome for the early diagnosis of $\mathrm{AD}$ has yet to be tested extensively, gene transcriptional profiles in the blood can reflect the complex pathophysiological status of $\mathrm{AD}$, suggesting the potential of blood as a tissue for investigating causative factors, disease mechanisms, biomarkers, and novel therapeutic targets for AD [9$10,8]$. Genes found to be expressed differently in the blood in AD are involved in biological pathways that have been associated with oxidative stress, mitochondrial dysfunction, immune activation, 
inflammation, apoptosis, cell cycle, transcription, ion channels, extracellular matrix components, neurological function, and other functional categories [4-6,8].

In a whole-genome brain transcriptome profiling study in patients with $\mathrm{AD}$, we previously described that calcium signaling was the most overrepresented altered pathway in the AD brain [11]. Thus, we wanted to explore if we could detect differences in the expression of genes related to this pathway in the peripheral blood. Moreover, mitochondrial dysfunction and autophagy have been related to the physiopathology of AD [12-13]. Therefore, we were also interested in studying the expression of genes from these pathways in the blood.

The aim of this study was to investigate if gene expression in the peripheral blood reflects AD-related changes in calcium-signaling, senescence and autophagy, and mitochondrial function/oxidative stress. Additionally, we searched for changes in the expression of two genes associated with an increased risk of developing $\mathrm{AD}$ ( $C L U$ and BIN1). These two genes do not belong to any of the biological pathways mentioned above, although $C L U$ can be related to the response to elevated platelet cytosolic $\mathrm{Ca}^{2+}$. We carefully selected our cohort, taking into account clinical and neuropsychological information together with the levels of AD biomarkers in the CSF (A $\beta 42$, t-tau, and p-tau). We specifically included a group of Pre-AD subjects, which to our best knowledge have not been studied in previous gene expression studies in the peripheral blood. In addition to assessing the differences in gene expression between clinical groups, we derived correlation networks for the studied genes to identify potential differences between patients with AD and controls.

\section{Materials and methods}

\section{Subjects}

Study subjects (total $\mathrm{N}=100$ ) were consecutively recruited at the Alzheimer's Disease and Other Cognitive Disorders Unit of the Hospital Clínic de Barcelona. Written informed consent was obtained for all subjects. Participants received a complete clinical and neuropsychological examination, magnetic resonance imaging, and a lumbar puncture. The determination of CSF biomarkers of AD (A $\beta 42, t$-tau, and p-tau) was used to create groups to increase the probability of an AD neuropathological substrate in the $\mathrm{AD}$ group, and to define the Pre-AD group (Table 1). 
The AD group $(\mathrm{N}=42)$ was defined according to the International Working Group (IWG)-2 criteria [14], requiring an $\mathrm{AD}$-compatible CSF signature: decreased CSF A $\beta 42$ levels plus high t-tau and p-tau levels. The Pre-AD group $(\mathrm{N}=11)$ was defined according to the National Institute on Aging-Alzheimer's Association NIA-AA criteria [3], which include cognitive performance within the normal range (performance within 1.5 standard deviations) in all tests from a specific test battery, no significant psychiatric symptoms or previous neurological disease, and decreased CSF A $\beta 42$. The control group $(\mathrm{N}=$ 47) consisted of cognitively healthy individuals without cognitive deficits or biomarker-level abnormalities. Demographic data and $A P O E$ genotypes are shown in Table 1.

\section{Cerebrospinal Fluid Analysis}

Cerebrospinal fluid (CSF) was collected by lumbar puncture between 9 am and $12 \mathrm{am}$. Samples were processed within 1 hour by centrifugation at $4^{\circ} \mathrm{C}$ for $10 \mathrm{~min}$ at $2000 \times \mathrm{g}$, stored in polypropylene tubes, and frozen at $-80^{\circ} \mathrm{C}$. Next, CSF $\mathrm{A} \beta 42$, p-tau, and t-tau levels were detected by enzyme-linked immunosorbent assay (ELISA) (Fujirebio Europe, Gent, Belgium). Biomarker cut-off values were 500 $\mathrm{pg} / \mathrm{mL}$ for $\mathrm{A} \beta 42,450 \mathrm{pg} / \mathrm{mL}$ for t-tau and $75 \mathrm{pg} / \mathrm{mL}$ for $\mathrm{p}$-tau [15].

\section{Whole Blood RNA Extraction}

Venous blood samples (3 mL) were drawn into Tempus Blood RNA tubes (Life technologies, Thermo Fisher Scientific, Waltham, MA, USA) and inverted 8-10 times. Tubes were frozen below $-20^{\circ} \mathrm{C}$ until RNA extraction. Total RNA was extracted using two Tempus tubes per subject and with the Tempus Spin RNA Isolation Kit (Life technologies) according to the manufacturer's instructions. RNA was stored at $-70^{\circ} \mathrm{C}$ or below, then concentrated using the RNA Clean \& Concentrator-5 Kit (Zymo Research, Irvine, CA, USA) and assessed for quality and quantity using the Nanodrop ND-1000 spectrophotometer (Thermo Fisher Scientific, Thermo Scientific, Waltham, MA, USA).

Quantitative Reverse-Transcription Polymerase Chain Reaction (qRT-PCR)

RNA $(1 \mu \mathrm{g})$ was retro-transcribed using the SuperScript ${ }^{\circledR}$ VILO $^{\text {TM }}$ cDNA synthesis kit following the manufacturer's instructions (Life technologies). A pre-amplification of 14 cycles was performed for all genes with a customized TaqMan® PreAmp Pool and TaqMan® PreAmp Master Mix (Life technologies) prior to quantitative PCR. Custom TaqMan® Array Cards (TACs) were designed with three reference genes (PPIB, PGK1, POLR2A) and 20 selected genes, classified into the following groups: calcium signaling (7 genes), mitochondria/oxidative stress (8 genes), senescence and autophagy (3 genes), and AD 
risk factor (2 genes) (Table 2). Reference genes for normalization were selected based on existing literature [16] and confirmed with a good stability score in Expression Suite software (Life technologies). Quantitative PCR with TACs was performed in a Viia7 instrument (Life technologies). All reactions were run in triplicate.

\section{Bioinformatics Analysis}

Quality control and statistical tests. Triplicate raw data cycle threshold (Ct) values of each sample were analyzed with Expression Suite software. These values were normalized with the mean Ct of the three endogenous genes (mean $\mathrm{Ct}$ value - mean $\mathrm{Ct}$ of endogenous genes $=\Delta \mathrm{Ct}$ value), and were further transformed to $2^{-\Delta \mathrm{Ct}}$. After a careful exploration of the quality of the normalized data, a generalized linear model analysis (ANOVA), adjusted for covariates (age as quantitative and $A P O E$ genotype as cathegorical), was used to calculate differences in expression between groups. P-values $<0.05$ were considered significant. The magnitude of change between groups was calculated with the $2^{-\Delta \Delta C t}$ method (mean $\Delta \mathrm{Ct}$ value of group $1-$ mean $\Delta \mathrm{Ct}$ value of group $2=\Delta \Delta \mathrm{Ct}$, further transformed to $2^{-\Delta \Delta \mathrm{Ct}}$ ). For the comparison of Pre-AD with controls or patients with AD, we selected groups of equal number $(\mathrm{N}=11)$ matched for age.

Pearson correlation and networks derivation. Pearson correlations between all genes were computed separately for both datasets, controls and patients with AD. Networks were constructed for any dataset and two genes were connected if their correlation was considered significant, having a p-value $<0.001$. Representation of the networks was accomplished with the Cytoscape(C) tool [17], an "open-source" platform which construct and manage networks. Finally, we performed a meta-analysis comparing the differences between the topology of the networks, mainly identifying differences on hubs (genes with a large number of connectivities).

\section{Results}

\section{Differential gene expression}

Patients with AD presented significantly downregulated expression of $B E C N 1$ (p-value $=0.038 ; \mathrm{FC}=$ $0.88)$ and $P R K C B($ p-value $=0.024 ; \mathrm{FC}=0.85)$ genes compared with the control group (Fig. $1 \mathrm{~A}, \mathrm{~B}$ and 
Fig. 2A). When using only age and not the APOE genotype as a covariate (ANOVA test), the $C L U$ gene also reached statistical significance between these groups ( $\mathrm{p}$-value $=0.013$ ).

The Pre-AD group presented significant differences in the expression and up-regulation of the $C D K N 2 A$ gene $(\mathrm{p}$-value $=0.028 ; \mathrm{FC}=1.70)$ compared with an equal number of age-matched controls $($ Fig. $1 \mathrm{C}$ and Fig. 2B). No significant differences in gene expression were detected between the matched Pre-AD and AD patient groups.

Gene-gene expression correlations

We looked for gene-gene expression correlations separately in the control $(\mathrm{N}=47)$ and $\mathrm{AD}(\mathrm{N}=42)$ groups. Initially, we focused on large correlations $(|R|>0.7)$ in at least one of the two groups and highlighted those where a clear difference existed between groups: BECN1-S100A6 (only present in AD), and ATP2B1-MAP1S and ATP2B1-PPP3R1 (only present in controls) (Table 3).

We then looked for all the correlations for the genes that were expressed statistically differently between $\mathrm{AD}$ and controls $(B E C N 1$ and $P R K C B)$ with an $|\mathrm{R}|>0.5$ and $\mathrm{p}<0.001$ in at least one of the two groups. From these correlations, we identified three differences: BECN1-S100A6 (already mentioned above), BECN1-ATP2B1 (present in AD), and PRKCB-MAP1S (present in controls). In addition, seven more correlations were common in the two groups, mostly for the PRKCB gene (6/7) (Table 3).

Cytoscape networks

Correlations with $|\mathrm{R}|>0.5$ and $\mathrm{p}<0.001$ were represented with the Cytoscape $\subset$ tool to visualize the networks for controls (Fig. 3A) and patients with $\mathrm{AD}$ (Fig. 3B). The network obtained for control subjects had largest coordination between the calcium-signaling and mitochondria/oxidative stress genes (12 positive inter-correlations) than that obtained for $\mathrm{AD}$ patients (7 positive inter-correlations ). Moreover, in the $\mathrm{AD}$ group, there were fewer connectivities between the mitochondria/oxidative stress genes compared with controls. We also identified gene hubs (largely connected genes) in both networks (ATP2B1, S100A6, CAPN1, PRKCB, and POLG), whereas other genes behaved as hub only in the controls and not in the patients with AD (PPP3R1, COX6B1, GPX3, and MAP1S). Finally, in the AD group, the links for the calcium-signaling gene, $C A C N A 1 B$, were lost. Inversely, new correlations appeared for the senescence and autophagy genes for patients with AD (three genes with five correlations), with only one gene connected in controls. 


\section{Discussion}

We detected significant differences in the expression of three genes (BECN1, PRKCB, and CDKN2A) in the blood of patients with $\mathrm{AD}$ and Pre-AD. Compared with controls, we demonstrated that $C D K N 2 A$ was expressed differently in the Pre-AD phase, while BECN1 and $P R K C B$ were expressed differently in patients with AD. BECN1 and $C D K N 2 A$ were related to the senescence and autophagy pathway, while PRKCB was related to the calcium-signaling pathway (http://pathcards.genecards.org/), although it can also play a role in autophagy and mitochondrial function [18]. Notably, these three genes are also considered tumor suppressor $(C D K N 2 A$ and $B E C N 1)$ or tumor promoter $(P R K C B)$ genes (http://www.genecards.org/).

A number of recent studies have revealed an inverse correlation in the prevalence of $\mathrm{AD}$ and cancer in multiple ethnic groups, with a reduced risk of developing cancer in patients with AD and a reduced risk of developing AD in those with a history of cancer [19]. In this sense, many genes regulating cell proliferation/survival or apoptosis are altered in AD brains, resulting in a prone-to-death state [20]. The re-expression of a multitude of cell-cycle regulators known to control the activation and progression of the cell cycle in dividing cells has been observed in degenerating AD neurons [21], suggesting a reactivation of the cell cycle during neurodegeneration [22-23,21]. After withdrawal from the cell cycle, differentiated neurons are able to alter molecular mechanisms that primarily control proliferation, to control synaptic plasticity instead $[21,23]$. The existence of these alternate effector pathways within a neuron might put it at risk and erroneously convert signals derived from plastic synaptic changes into positional cues that will activate the cell cycle. This cell-cycle activation can potentially link synaptic plasticity to cell death [21]. Indeed, aberrant reentry to the cell cycle may be an early pathogenic event of $\mathrm{AD}$, and could be detectable in the brains of patients with mild cognitive impairment and pathological evidence of $\mathrm{AD}[24]$.

The CDKN2A gene codes for the Cyclin-Dependent Kinase Inhibitor 2A (CDKN2A) protein. It is a tumor suppressor gene involved in cell-cycle regulation, and is frequently mutated or deleted in several tumors. Interestingly, our study is the first to describe altered $C D K N 2 A$ levels in the blood of patients with preAD compared with controls. This suggests that $C D K N 2 A$ could be considered as a potential biomarker or therapeutic target in the earlier stages of the disease; but, more evidence is needed using larger cohorts. The CDKN2A protein has previously been reported to be up-regulated in the brains of patients with AD [25], as well as in brain and peripheral cells from the amyloid precursor protein/presenilin 1 mouse model 
of $\mathrm{AD}$ [26]. However, we did not detect any differences in $C D K N 2 A$ gene expression between our control and AD groups. This discrepancy from the previous studies could be explained by differences in the tissue/animal model studied and in the targeted molecule (mRNA or protein). Equally, the fact that we detected mRNA expression differences in the blood of the Pre-AD group makes us consider that it is possible to detect differences using this model. Thus, we hypothesize that the differences are bigger in the Pre-AD phase than when $\mathrm{AD}$ is present (with respect to controls), which would explain why we only have been able to detect them in blood of patients in the Pre-AD phase. Another possible explanation for this unexpected finding when comparing Controls and $\mathrm{AD}$ groups (with bigger sample size than the Pre-AD) would be the inter-individual variability in the values of $C D K N 2 A$ expression within a group and the wider range of age. Other studies have revealed alterations of cell-cycle regulating proteins (p53, p21, phosphorylated forms p53 [ser15] and p21 [thr145], CDK2, E 2 F-1, Cyclin E, Rb and CDKN1B) in peripheral blood lymphocytes of patients with AD [27-29]. These studies, together with our findings, suggest that the use of peripheral cells to study the molecular basis of AD pathogenesis, including cellcycle disturbances, can be a valuable resource.

The PRKCB gene encodes the beta protein of the Protein Kinase C (PKC) family of serine- and threoninespecific protein kinases that can be activated by calcium and the second messenger diacylglycerol. Although PKC over-expression has been shown to contribute to cell transformation, PKCs are not considered classic oncogenes that are activated by mutations, but are considered tumor promoters that enhance multiple cellular signaling pathways [30]. We have found evidence of $P R K C B$ gene downregulation in patients with $\mathrm{AD}$. However, the role of $P R K C B$ in the development of $\mathrm{AD}$ is ambiguous, because some contradictory results exist as to whether it is up- or downregulated [31-33]. This could be explained by differences in studied tissue, mRNA or protein analysis, and experimental protocols.

Autophagy is a major intracellular degradation pathway that plays an essential role in the cellular stress response. Autophagy degrades intracellular components, including whole organelles, allowing building blocks and energy to be released to maintain cellular homeostasis [34]. Several pathologies (including various types of cancer and neurodegenerative disorders such as AD) are characterized by altered levels of autophagy. The BECN1 gene, which encodes the Beclin-1 protein, is a tumor suppressor gene that participates in the regulation of autophagy and has an important role in development, tumor genesis, and neurodegeneration [35]. We identified BECN1 downregulation in patients with AD, consistent with 
previous literature that have indicated that expression of the Beclin-1 protein is reduced in the brains of patients with $\mathrm{AD}[12,36]$. We have been unable to identify any data concerning its expression in the blood.

Several reports have described increased CLU protein concentration in different brain areas. However, there is some controversy as to whether it is increased in the frontal cortex in AD and whether it is associated with the $A P O E \& 4$ load [37-40]. Moreover, increased plasma CLU concentration has been reported in $\mathrm{AD}$ to predict greater beta amyloid $(\mathrm{A} \beta)$ burden in the medial temporal lobe [41] as well as brain atrophy in mild cognitive impairment [42]. We analyzed the differences in $C L U$ gene expression in the blood, but it only reached statistical significance when using age as a covariate $(p$-value $=0.013$ ), with a trend when using $A P O E$ as a covariate (p-value $=0.07$ ). Thus, the $A P O E$ genotype may be important when considering $C L U$ levels as a possible biomarker. The role of $C L U$ should be explored in more depth to clarify its potential role as a blood biomarker.

Gene expression correlation networks were created for the 20 genes selected for this study. Although they represent a small proportion of the genome, we detected different correlations between the control group and patients with AD. These could represent functional relations that are gained or lost in patients with $\mathrm{AD}$, and that could be targets for research or therapy. Gene-gene significant correlations present in controls only (i.e., PRKCB-MAP1S, ATP2B1-MAP1S, and ATP2B1-PPP3R1), and not in patients with $\mathrm{AD}$, could describe important relationships for healthy aging. Conversely, gene-gene significant correlations present only in patients with AD (i.e., BECN1-S100A6 and BECN1-ATP2B1) could be important for the development of the disease or could be a consequence of the disease. Some genes were hubs (largely interconnected features) only in one of the groups, but the $P R K C B$ gene was a hub in both networks, and had a relatively high number of connectivities with genes involved in mitochondrial function, such as POLG, GPX3, MAP1S, and COX6B1. In this sense, many inter-correlations exist between calcium-signaling and mitochondria/oxidative stress functional groups, with a higher number in controls than in patients with AD. While the correlations were present in both networks (controls and AD) for the calcium-signaling genes, the correlations were diminished in the AD network for the mitochondria/oxidative stress genes, which indicates that the uncoupling of genes from these functional groups could be relevant for the disease state.

We are aware that the present study has some limitations. First, our Pre-AD group had a reduced sample size because it was difficult to identify potential subjects that met all the inclusion criteria. Second, when 
assessed in blood, gene expression may be influenced by the cellular diversity of the blood compartment; several additional factors can contribute to the individual variability in gene expression, such as diet, exercise, treatment or inflammatory events. Finally, for the genes with a statistically significant difference, there exists an overlap among participant groups, which makes them unsuitable for use as diagnostic biomarkers. Nevertheless, we believe that they are very useful for continue to advance our knowledge of the physiopathology of AD.

In conclusion, we studied the expression of genes in the peripheral blood at different stages of AD. We detected significant differences in the expression of genes related to calcium signaling, senescence and autophagy. Notably, all identified genes were related to cancer, strengthening the argument that more studies are needed to investigate the relationship between neurodegenerative diseases and cancer. Due to its accessibility, whole blood represents a valuable tissue that can be used to advance our knowledge of the pathophysiology of $\mathrm{AD}$ and, potentially, to find a biomarker for $\mathrm{AD}$.

\section{References}

1. Braak H, Alafuzoff I, Arzberger T, Kretzschmar H, Del Tredici K (2006) Staging of Alzheimer disease-associated neurofibrillary pathology using paraffin sections and immunocytochemistry. Acta Neuropathol 112 (4):389-404. doi:10.1007/s00401-006$0127-\mathrm{z}$

2. Jack CR, Jr., Knopman DS, Jagust WJ, Shaw LM, Aisen PS, Weiner MW, Petersen RC, Trojanowski JQ (2010) Hypothetical model of dynamic biomarkers of the Alzheimer's pathological cascade. Lancet Neurol 9 (1):119-128. doi:S14744422(09)70299-6 [pii] 10.1016/S1474-4422(09)70299-6

3. Sperling RA, Aisen PS, Beckett LA, Bennett DA, Craft S, Fagan AM, Iwatsubo T, Jack CR, Jr., Kaye J, Montine TJ, Park DC, Reiman EM, Rowe CC, Siemers E, Stern Y, Yaffe K, Carrillo MC, Thies B, Morrison-Bogorad M, Wagster MV, Phelps CH (2011) Toward defining the preclinical stages of Alzheimer's disease: recommendations from the National Institute on Aging-Alzheimer's Association workgroups on diagnostic guidelines for Alzheimer's disease. Alzheimers Dement 7 (3):280-292. doi:S15525260(11)00099-9 [pii] 10.1016/j.jalz.2011.03.003

4. Fehlbaum-Beurdeley P, Jarrige-Le Prado AC, Pallares D, Carriere J, Guihal C, Soucaille C, Rouet F, Drouin D, Sol O, Jordan H, Wu D, Lei L, Einstein R, Schweighoffer F, Bracco L (2010) Toward an Alzheimer's disease diagnosis via highresolution blood gene expression. Alzheimers Dement 6 (1):25-38. doi:S15525260(09)02089-5 [pii] 10.1016/j.jalz.2009.07.001

5. Booij BB, Lindahl T, Wetterberg P, Skaane NV, Saebo S, Feten G, Rye PD, Kristiansen LI, Hagen N, Jensen M, Bardsen K, Winblad B, Sharma P, Lonneborg A 
(2011) A gene expression pattern in blood for the early detection of Alzheimer's disease. J Alzheimers Dis 23 (1):109-119. doi:W413U3248K01W27Q [pii] 10.3233/JAD-2010-101518

6. Rye PD, Booij BB, Grave G, Lindahl T, Kristiansen L, Andersen HM, Horndalsveen PO, Nygaard HA, Naik M, Hoprekstad D, Wetterberg P, Nilsson C, Aarsland D,

Sharma P, Lonneborg A (2011) A novel blood test for the early detection of Alzheimer's disease. J Alzheimers Dis 23 (1):121-129. doi:W4H554U72110W857 [pii]

10.3233/JAD-2010-101521

7. Lunnon K, Sattlecker M, Furney SJ, Coppola G, Simmons A, Proitsi P, Lupton MK, Lourdusamy A, Johnston C, Soininen H, Kloszewska I, Mecocci P, Tsolaki M, Vellas B, Geschwind D, Lovestone S, Dobson R, Hodges A (2013) A blood gene expression marker of early Alzheimer's disease. J Alzheimers Dis 33 (3):737-753. doi:R36932421476K620 [pii]

10.3233/JAD-2012-121363

8. Naughton BJ, Duncan FJ, Murrey DA, Meadows AS, Newsom DE, Stoicea N, White P, Scharre DW, McCarty DM, Fu H (2014) Blood Genome-Wide Transcriptional Profiles Reflect Broad Molecular Impairments and Strong Blood-Brain Links in Alzheimer's Disease. J Alzheimers Dis. doi:FK85177375240413 [pii] 10.3233/JAD-140606

9. Maes OC, Xu S, Yu B, Chertkow HM, Wang E, Schipper HM (2007) Transcriptional profiling of Alzheimer blood mononuclear cells by microarray. Neurobiol Aging 28 (12):1795-1809. doi:S0197-4580(06)00298-3 [pii]

10.1016/j.neurobiolaging.2006.08.004

10. Han G, Wang J, Zeng F, Feng X, Yu J, Cao HY, Yi X, Zhou H, Jin LW, Duan Y, Wang YJ, Lei H (2013) Characteristic transformation of blood transcriptome in Alzheimer's disease. J Alzheimers Dis 35 (2):373-386. doi:3685X227K52688P6 [pii] 10.3233/JAD-121963

11. Antonell A, Llado A, Altirriba J, Botta-Orfila T, Balasa M, Fernandez M, Ferrer I, Sanchez-Valle R, Molinuevo JL (2013) A preliminary study of the whole-genome expression profile of sporadic and monogenic early-onset Alzheimer's disease.

Neurobiol Aging 34 (7):1772-1778. doi:S0197-4580(12)00659-8 [pii]

10.1016/j.neurobiolaging.2012.12.026

12. Salminen A, Kaarniranta K, Kauppinen A, Ojala J, Haapasalo A, Soininen H,

Hiltunen M (2013) Impaired autophagy and APP processing in Alzheimer's disease: The potential role of Beclin 1 interactome. Prog Neurobiol 106-107:33-54. doi:S03010082(13)00051-8 [pii] 10.1016/j.pneurobio.2013.06.002

13. Garcia-Escudero V, Martin-Maestro P, Perry G, Avila J (2013) Deconstructing mitochondrial dysfunction in Alzheimer disease. Oxid Med Cell Longev 2013:162152. doi: $10.1155 / 2013 / 162152$

14. Dubois B, Feldman HH, Jacova C, Hampel H, Molinuevo JL, Blennow K, DeKosky ST, Gauthier S, Selkoe D, Bateman R, Cappa S, Crutch S, Engelborghs S, Frisoni GB, Fox NC, Galasko D, Habert MO, Jicha GA, Nordberg A, Pasquier F, Rabinovici G, Robert P, Rowe C, Salloway S, Sarazin M, Epelbaum S, de Souza LC, Vellas B, Visser PJ, Schneider L, Stern Y, Scheltens P, Cummings JL (2014) Advancing research diagnostic criteria for Alzheimer's disease: the IWG-2 criteria. Lancet Neurol 13 (6):614-629. doi:S1474-4422(14)70090-0 [pii] 10.1016/S1474-4422(14)70090-0

15. Antonell A, Fortea J, Rami L, Bosch B, Balasa M, Sanchez-Valle R, Iranzo A, Molinuevo JL, Llado A (2011) Different profiles of Alzheimer's disease cerebrospinal 
fluid biomarkers in controls and subjects with subjective memory complaints. J Neural Transm 118 (2):259-262. doi:10.1007/s00702-010-0534-0

16. Falkenberg VR, Whistler T, Murray JR, Unger ER, Rajeevan MS (2011)

Identification of Phosphoglycerate Kinase 1 (PGK1) as a reference gene for quantitative gene expression measurements in human blood RNA. BMC Res Notes 4:324. doi:17560500-4-324 [pii]

10.1186/1756-0500-4-324

17. Shannon P, Markiel A, Ozier O, Baliga NS, Wang JT, Ramage D, Amin N, Schwikowski B, Ideker T (2003) Cytoscape: a software environment for integrated models of biomolecular interaction networks. Genome Res 13 (11):2498-2504.

doi:10.1101/gr.1239303

13/11/2498 [pii]

18. Patergnani S, Marchi S, Rimessi A, Bonora M, Giorgi C, Mehta KD, Pinton P (2013) PRKCB/protein kinase $\mathrm{C}$, beta and the mitochondrial axis as key regulators of autophagy. Autophagy 9 (9):1367-1385. doi:25239 [pii]

10.4161/auto.25239

19. Li JM, Liu C, Hu X, Cai Y, Ma C, Luo XG, Yan XX (2014) Inverse correlation between Alzheimer inverted question marks disease and cancer: implication for a strong impact of regenerative propensity on neurodegeneration? BMC Neurol 14 (1):211. doi:s12883-014-0211-2 [pii]

10.1186/s12883-014-0211-2

20. Behrens MI, Lendon C, Roe CM (2009) A common biological mechanism in cancer and Alzheimer's disease? Curr Alzheimer Res 6 (3):196-204

21. Arendt T (2012) Cell cycle activation and aneuploid neurons in Alzheimer's disease. Mol Neurobiol 46 (1):125-135. doi:10.1007/s12035-012-8262-0

22. Herrup K, Arendt T (2002) Re-expression of cell cycle proteins induces neuronal cell death during Alzheimer's disease. J Alzheimers Dis 4 (3):243-247

23. Arendt T, Bruckner MK (2007) Linking cell-cycle dysfunction in Alzheimer's disease to a failure of synaptic plasticity. Biochim Biophys Acta 1772 (4):413-421. doi:S0925-4439(06)00269-9 [pii]

10.1016/j.bbadis.2006.12.005

24. Yang Y, Mufson EJ, Herrup K (2003) Neuronal cell death is preceded by cell cycle events at all stages of Alzheimer's disease. J Neurosci 23 (7):2557-2563. doi:23/7/2557 [pii]

25. McShea A, Harris PL, Webster KR, Wahl AF, Smith MA (1997) Abnormal expression of the cell cycle regulators P16 and CDK4 in Alzheimer's disease. Am J Pathol 150 (6):1933-1939

26. Esteras N, Bartolome F, Alquezar C, Antequera D, Munoz U, Carro E, MartinRequero A (2012) Altered cell cycle-related gene expression in brain and lymphocytes from a transgenic mouse model of Alzheimer's disease [amyloid precursor protein/presenilin 1 (PS1)]. Eur J Neurosci 36 (5):2609-2618. doi:10.1111/j.14609568.2012.08178.x

27. Tan M, Wang S, Song J, Jia J (2012) Combination of p53(ser15) and p21/p21(thr145) in peripheral blood lymphocytes as potential Alzheimer's disease biomarkers. Neurosci Lett 516 (2):226-231. doi:S0304-3940(12)00491-0 [pii] 10.1016/j.neulet.2012.03.093

28. Song J, Wang S, Tan M, Jia J (2012) G1/S checkpoint proteins in peripheral blood lymphocytes are potentially diagnostic biomarkers for Alzheimer's disease. Neurosci Lett 526 (2):144-149. doi:S0304-3940(12)01086-5 [pii] 10.1016/j.neulet.2012.08.020 
29. de las Cuevas N, Urcelay E, Hermida OG, Saiz-Diaz RA, Bermejo F, Ayuso MS, Martin-Requero A (2003) Ca2+/calmodulin-dependent modulation of cell cycle elements $\mathrm{pRb}$ and $\mathrm{p} 27 \mathrm{kip} 1$ involved in the enhanced proliferation of lymphoblasts from patients with Alzheimer dementia. Neurobiol Dis 13 (3):254-263.

doi:S0969996103000408 [pii]

30. Martiny-Baron G, Fabbro D (2007) Classical PKC isoforms in cancer. Pharmacol

Res 55 (6):477-486. doi:S1043-6618(07)00079-5 [pii]

10.1016/j.phrs.2007.04.001

31. Masliah E, Cole G, Shimohama S, Hansen L, DeTeresa R, Terry RD, Saitoh T

(1990) Differential involvement of protein kinase C isozymes in Alzheimer's disease. J

Neurosci 10 (7):2113-2124

32. Alldred MJ, Duff KE, Ginsberg SD (2012) Microarray analysis of CA1 pyramidal neurons in a mouse model of tauopathy reveals progressive synaptic dysfunction.

Neurobiol Dis 45 (2):751-762. doi:S0969-9961(11)00354-8 [pii]

10.1016/j.nbd.2011.10.022

33. Gerschutz A, Heinsen H, Grunblatt E, Wagner AK, Bartl J, Meissner C, Fallgatter AJ, Al-Sarraj S, Troakes C, Ferrer I, Arzberger T, Deckert J, Riederer P, Fischer M,

Tatschner T, Monoranu CM (2014) Neuron-specific alterations in signal transduction pathways associated with Alzheimer's disease. J Alzheimers Dis 40 (1):135-142. doi:M330NL5304413834 [pii]

10.3233/JAD-131280

34. Boya P, Reggiori F, Codogno P (2013) Emerging regulation and functions of autophagy. Nat Cell Biol 15 (7):713-720. doi:ncb2788 [pii]

$10.1038 / \mathrm{ncb} 2788$

35. Zhong Y, Wang QJ, Li X, Yan Y, Backer JM, Chait BT, Heintz N, Yue Z (2009)

Distinct regulation of autophagic activity by Atg14L and Rubicon associated with

Beclin 1-phosphatidylinositol-3-kinase complex. Nat Cell Biol 11 (4):468-476.

doi:ncb1854 [pii]

$10.1038 /$ ncb1854

36. Pickford F, Masliah E, Britschgi M, Lucin K, Narasimhan R, Jaeger PA, Small S, Spencer B, Rockenstein E, Levine B, Wyss-Coray T (2008) The autophagy-related protein beclin 1 shows reduced expression in early Alzheimer disease and regulates amyloid beta accumulation in mice. J Clin Invest 118 (6):2190-2199.

doi:10.1172/JCI33585

37. Lidstrom AM, Bogdanovic N, Hesse C, Volkman I, Davidsson P, Blennow K (1998) Clusterin (apolipoprotein J) protein levels are increased in hippocampus and in frontal cortex in Alzheimer's disease. Exp Neurol 154 (2):511-521. doi:S00144886(98)96892-3 [pii]

10.1006/exnr.1998.6892

38. Bertrand P, Poirier J, Oda T, Finch CE, Pasinetti GM (1995) Association of apolipoprotein $\mathrm{E}$ genotype with brain levels of apolipoprotein $\mathrm{E}$ and apolipoprotein $\mathrm{J}$ (clusterin) in Alzheimer disease. Brain Res Mol Brain Res 33 (1):174-178. doi:0169328X9500097C [pii]

39. Harr SD, Uint L, Hollister R, Hyman BT, Mendez AJ (1996) Brain expression of apolipoproteins E, J, and A-I in Alzheimer's disease. J Neurochem 66 (6):2429-2435 40. Baig S, Palmer LE, Owen MJ, Williams J, Kehoe PG, Love S (2012) Clusterin mRNA and protein in Alzheimer's disease. J Alzheimers Dis 28 (2):337-344. doi:76N6N165XL685831 [pii]

10.3233/JAD-2011-110473 
41. Thambisetty M, Simmons A, Velayudhan L, Hye A, Campbell J, Zhang Y, Wahlund LO, Westman E, Kinsey A, Guntert A, Proitsi P, Powell J, Causevic M, Killick R, Lunnon K, Lynham S, Broadstock M, Choudhry F, Howlett DR, Williams RJ, Sharp SI, Mitchelmore C, Tunnard C, Leung R, Foy C, O'Brien D, Breen G, Furney SJ, Ward M, Kloszewska I, Mecocci P, Soininen H, Tsolaki M, Vellas B, Hodges A, Murphy DG, Parkins S, Richardson JC, Resnick SM, Ferrucci L, Wong DF, Zhou Y, Muehlboeck S, Evans A, Francis PT, Spenger C, Lovestone S (2010) Association of plasma clusterin concentration with severity, pathology, and progression in Alzheimer disease. Arch Gen Psychiatry 67 (7):739-748. doi:67/7/739 [pii]

10.1001/archgenpsychiatry.2010.78

42. Thambisetty M, An Y, Kinsey A, Koka D, Saleem M, Guntert A, Kraut M, Ferrucci L, Davatzikos C, Lovestone S, Resnick SM (2012) Plasma clusterin concentration is associated with longitudinal brain atrophy in mild cognitive impairment. Neuroimage 59 (1):212-217. doi:S1053-8119(11)00833-0 [pii]

10.1016/j.neuroimage.2011.07.056 


\section{TABLES}

Table 1. Demographic and clinical/biochemical characteristics of participants, divided in the main three groups: Controls, AD (Alzheimer's disease patients) and Pre-AD (Preclinical AD)

\begin{tabular}{lccc}
\hline & Control & AD & Pre-AD \\
\hline $\mathbf{n}$ & 47 & 42 & 11 \\
\hline $\begin{array}{l}\text { Gender } \\
\text { (Male/Female) }\end{array}$ & $17 / 30$ & $13 / 29$ & $2 / 9$ \\
\hline Age (years) & 63.58 & 66.14 & 69.59 \\
& $(7.2)$ & $(8.5)$ & $(8.3)$ \\
\hline APOE (\% 84) & 14.9 & 54.76 & 27.27 \\
\hline MMSE score & 28.55 & 23.03 & 27.55 \\
& $(1.5)$ & $(5.2)$ & $(1.4)$ \\
\hline CSF A $\beta 42$ & 799.12 & 371.30 & 389.83 \\
(pg/mL) & $(213.3)$ & $(75.9)$ & $(96.8)$ \\
\hline CSF t-tau & 237.81 & 844.50 & 280.58 \\
(pg/mL) & $(67.0)$ & $(360.9)$ & $(164.0)$ \\
\hline CSF p-tau & 52.21 & 115.23 & 59.74 \\
(pg/mL) & $(10.7)$ & $(47.8)$ & $(27.0)$ \\
\hline
\end{tabular}

Values are shown as mean $( \pm \mathrm{SD})$ for age, MMSE score, and CSF AD biomarkers. APOE genotype is given as the percentage of $\varepsilon 4$ allele carriers ( $\% \varepsilon 4)$. Key: CSF, cerebrospinal fluid 
Table 2. Details of the selected genes

\begin{tabular}{|c|c|c|c|}
\hline Gene symbol & Description & $\begin{array}{l}\text { Group } \\
\text { classification }\end{array}$ & $\begin{array}{l}\text { Life technologies } \\
\text { assay number }\end{array}$ \\
\hline CALM3 & $\begin{array}{l}\text { Calmodulin } 3 \\
\text { (phosphorylase kinase, } \\
\text { delta) }\end{array}$ & Calcium signaling & Hs00968732_g1 \\
\hline CACNA1B & $\begin{array}{l}\text { Calcium Channel, Voltage- } \\
\text { Dependent, N Type, Alpha } \\
\text { 1B Subunit }\end{array}$ & Calcium signaling & Hs01053090_m1 \\
\hline PPP3R1 & $\begin{array}{l}\text { Protein Phosphatase 3, } \\
\text { Regulatory Subunit B, Alpha }\end{array}$ & Calcium signaling & Hs01547793_m1 \\
\hline ATP2B1 & $\begin{array}{l}\text { ATPase, Ca++ Transporting, } \\
\text { Plasma Membrane }\end{array}$ & Calcium signaling & Hs00155949_m1 \\
\hline PRKCB & Protein Kinase C, Beta & Calcium signaling & Hs00176998_m1 \\
\hline CAPN1 & Calpain 1 & Calcium signaling & Hs00559804_m1 \\
\hline S100A6 & $\begin{array}{l}\text { S100 calcium binding } \\
\text { protein } A 6\end{array}$ & Calcium signaling & Hs00170953_m1 \\
\hline BECN1 & Beclin-1, autophagy related & $\begin{array}{l}\text { Senescence and } \\
\text { autophagy }\end{array}$ & Hs00186838_m1 \\
\hline ATG5 & Autophagy related 5 & $\begin{array}{l}\text { Senescence and } \\
\text { autophagy }\end{array}$ & Hs00169468_m1 \\
\hline CDKN2A & $\begin{array}{l}\text { Cyclin-dependent kinase } \\
\text { inhibitor } 2 \mathrm{~A}\end{array}$ & $\begin{array}{l}\text { Senescence and } \\
\text { autophagy }\end{array}$ & Hs02902543_mH \\
\hline CLU & Clusterin & $A D$ risk factor gene & Hs00971656_m1 \\
\hline BIN1 & Bridging Integrator 1 & $A D$ risk factor gene & Hs00184913_m1 \\
\hline HSD17B10 & $\begin{array}{l}\text { Hydroxysteroid (17-beta) } \\
\text { dehydrogenase } 10\end{array}$ & $\begin{array}{l}\text { Mitochondria and } \\
\text { oxidative stress }\end{array}$ & Hs00189576_m1 \\
\hline POLG & $\begin{array}{l}\text { Polymerase (DNA directed), } \\
\text { gamma }\end{array}$ & $\begin{array}{l}\text { Mitochondria and } \\
\text { oxidative stress }\end{array}$ & Hs01018668_m1 \\
\hline MAP1S & $\begin{array}{l}\text { Microtubule-associated } \\
\text { protein 1S }\end{array}$ & $\begin{array}{l}\text { Mitochondria and } \\
\text { oxidative stress }\end{array}$ & Hs00430193_m1 \\
\hline CoX6B1 & $\begin{array}{l}\text { Cytochrome c oxidase } \\
\text { subunit VIb polypeptide } 1 \\
\text { (ubiquitous) }\end{array}$ & $\begin{array}{l}\text { Mitochondria and } \\
\text { oxidative stress }\end{array}$ & Hs00266375_m1 \\
\hline GPX3 & glutathione peroxidase 3 & $\begin{array}{l}\text { Mitochondria and } \\
\text { oxidative stress }\end{array}$ & Hs01078668_m1 \\
\hline SOD1 & $\begin{array}{l}\text { Superoxide dismutase } 1 \text {, } \\
\text { soluble }\end{array}$ & $\begin{array}{l}\text { Mitochondria and } \\
\text { oxidative stress }\end{array}$ & Hs00533490_m1 \\
\hline TOMM40 & $\begin{array}{l}\text { Translocase of outer } \\
\text { mitochondrial membrane } 40 \\
\text { homolog }\end{array}$ & $\begin{array}{l}\text { Mitochondria and } \\
\text { oxidative stress }\end{array}$ & Hs00746704_s1 \\
\hline PPARGC1A & $\begin{array}{l}\text { Peroxisome proliferator- } \\
\text { activated receptor gamma, } \\
\text { coactivator one alpha }\end{array}$ & $\begin{array}{l}\text { Mitochondria and } \\
\text { oxidative stress }\end{array}$ & Hs01016719_m1 \\
\hline POLR2A & $\begin{array}{l}\text { Polymerase (RNA) II (DNA } \\
\text { directed) polypeptide A }\end{array}$ & Reference gene & Hs01108291_m1 \\
\hline PPIB & Peptidylpropyl isomerase B & Reference gene & Hs00168719_m1 \\
\hline PGK1 & Phosphoglycerate kinase 1 & Reference gene & Hs00943178_g1 \\
\hline
\end{tabular}


Table 3. Correlations between the control and AD groups

\begin{tabular}{|c|c|c|c|c|}
\hline Correlation & R Controls & $\begin{array}{l}\text { p-value } \\
\text { Controls }\end{array}$ & R AD & p-value AD \\
\hline \multicolumn{5}{|c|}{ Largest different correlations $(|R|>0.7)$} \\
\hline ATP2B1-MAP1S & 0.73 & $3.18 \mathrm{E}-09$ & -0.08 & 0.59 \\
\hline ATP2B1-PPP3R1 & 0.82 & $3.91 \mathrm{E}-13$ & 0.39 & 0.007 \\
\hline BECN1-S100A6 & 0.38 & 0.007 & 0.71 & $1.96 \mathrm{E}-08$ \\
\hline \multicolumn{5}{|c|}{ BECN1 and PRKCB different correlations $(|R|>0.5)$} \\
\hline BECN1-ATP2B1 & -0.21 & 0.14 & -0.6 & 0.00044 \\
\hline PRKCB-MAP1S & 0.55 & $3.51 E-05$ & 0.06 & 0.7 \\
\hline \multicolumn{5}{|c|}{ BECN1 and PRKCB common correlations $(|R|>0.5)$} \\
\hline BECN1-CLU & 0.51 & 0.00019 & 0.5 & 0.00036 \\
\hline PRKCB-COX6B1 & 0.63 & $1.18 \mathrm{E}-06$ & 0.45 & 0.0013 \\
\hline PRKCB-POLG & 0.61 & $2.13 E-06$ & 0.61 & $5.26 \mathrm{E}-06$ \\
\hline PRKCB-GPX3 & 0.78 & $2.63 \mathrm{E}-11$ & 0.66 & 3.99E-07 \\
\hline PRKCB-S100A6 & -0.59 & $7.81 \mathrm{E}-06$ & -0.62 & $2.27 \mathrm{E}-06$ \\
\hline PRKCB-PPP3R1 & 0.66 & $2.51 \mathrm{E}-07$ & 0.51 & 0.00024 \\
\hline PRKCB-ATP2B1 & 0.69 & $2.78 \mathrm{E}-08$ & 0.62 & $2.72 \mathrm{E}-06$ \\
\hline
\end{tabular}

Strong correlations $(|\mathrm{R}|>0.7)$ are shown between controls and AD groups. Correlations between $P R K C B$ and BECN1 genes, with $\mathrm{p}<0.001$ and $|\mathrm{R}|>0.5$, were common (present in both groups) or different (present only in controls or AD). $|\mathrm{R}|$ value and $\mathrm{p}$-value are shown per group. Abbreviations: AD:

Alzheimer's disease. 


\section{FIGURE LEGENDS}

Fig. 1 Gene expression levels in peripheral blood (a.u.: arbitrary units; $\left.2^{-\Delta \mathrm{Ct} *} 1000\right)$ of the three significantly different genes: A) $B E C N 1$; B) $P R K C B$; C) $C D K N 2 A$. Mean $\pm 95 \%$ confidence intervals (CI) and significant p-values are shown. Key: CTRLs, Controls $(\mathrm{N}=47$ for $B E C N 1$ and $P R K C B ; \mathrm{N}=11$ for $C D K N 2 A)$; Pre-AD, patients with preclinical $\mathrm{AD}(\mathrm{N}=11)$; $\mathrm{AD}$, patients with Alzheimer's disease $(\mathrm{N}$ =42)

Fig. 2 Fold-change $\left(2^{-\Delta \Delta C t}\right)$ of the 20 genes that were studied. A) Comparison of AD $(N=42)$ and controls ( $\mathrm{N}=47)$. B) Comparison of pre-AD and controls $(\mathrm{N}=11)$. Key, CTRLs, Controls; AD, Alzheimer's disease

Fig. 3 Cytoscape networks representing significant correlations for gene-gene expression. Continuous lines represent positive correlations and discontinuous lines represent negative correlations. The thickness of the line is proportional to the strength of the correlation. Colors represent the functional group classification of a gene: yellow, calcium signaling; purple, mitochondria/oxidative stress; blue, senescence and autophagy; red, risk factor genes for Alzheimer's disease 
A

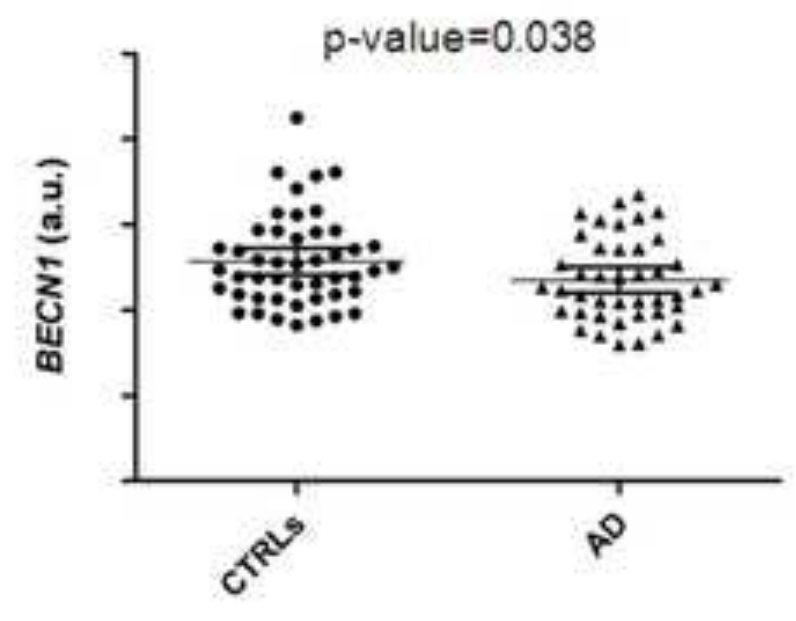

B

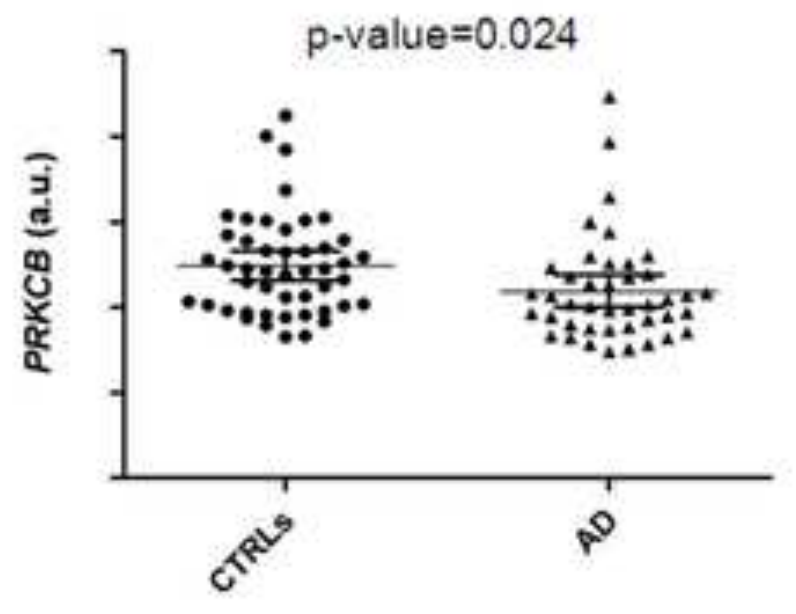

C

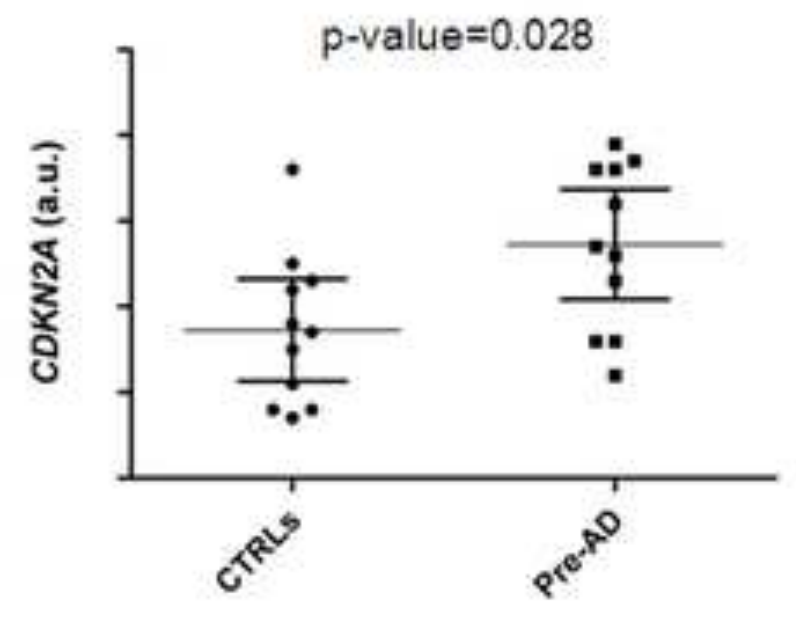


A

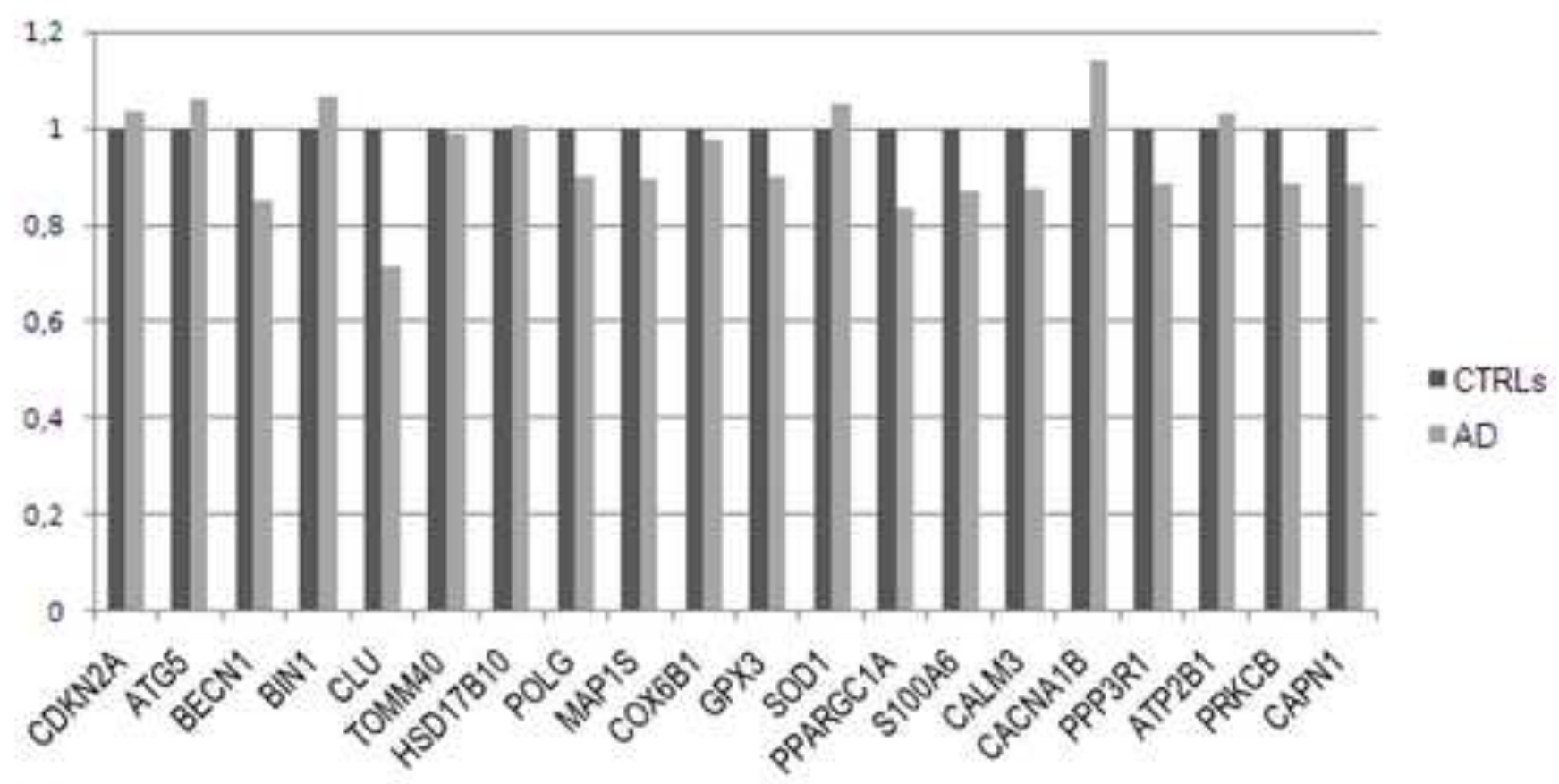

B

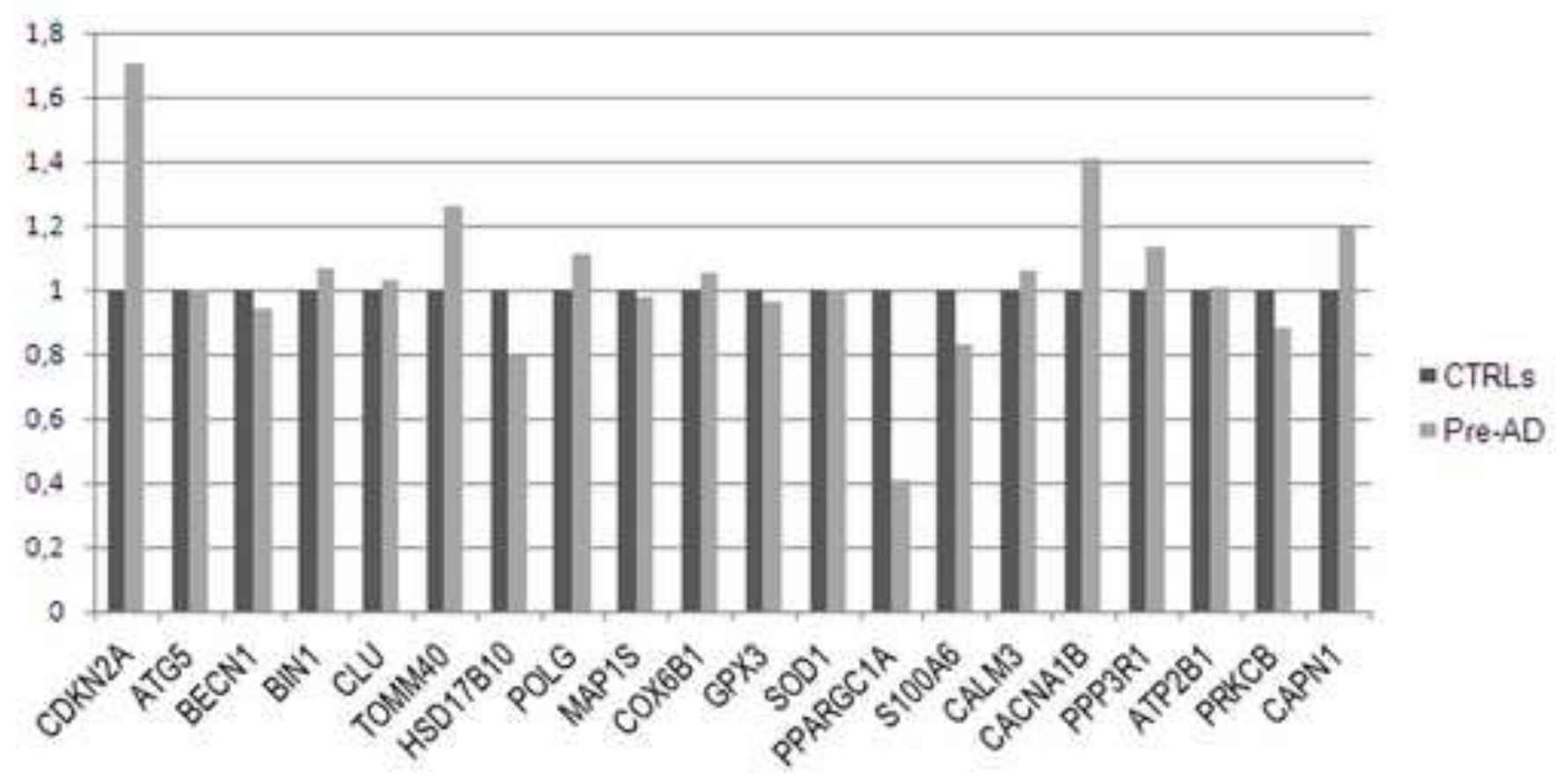


Figure 3

Click here to download Figure: Fig 3_Antonell.jpg

A)

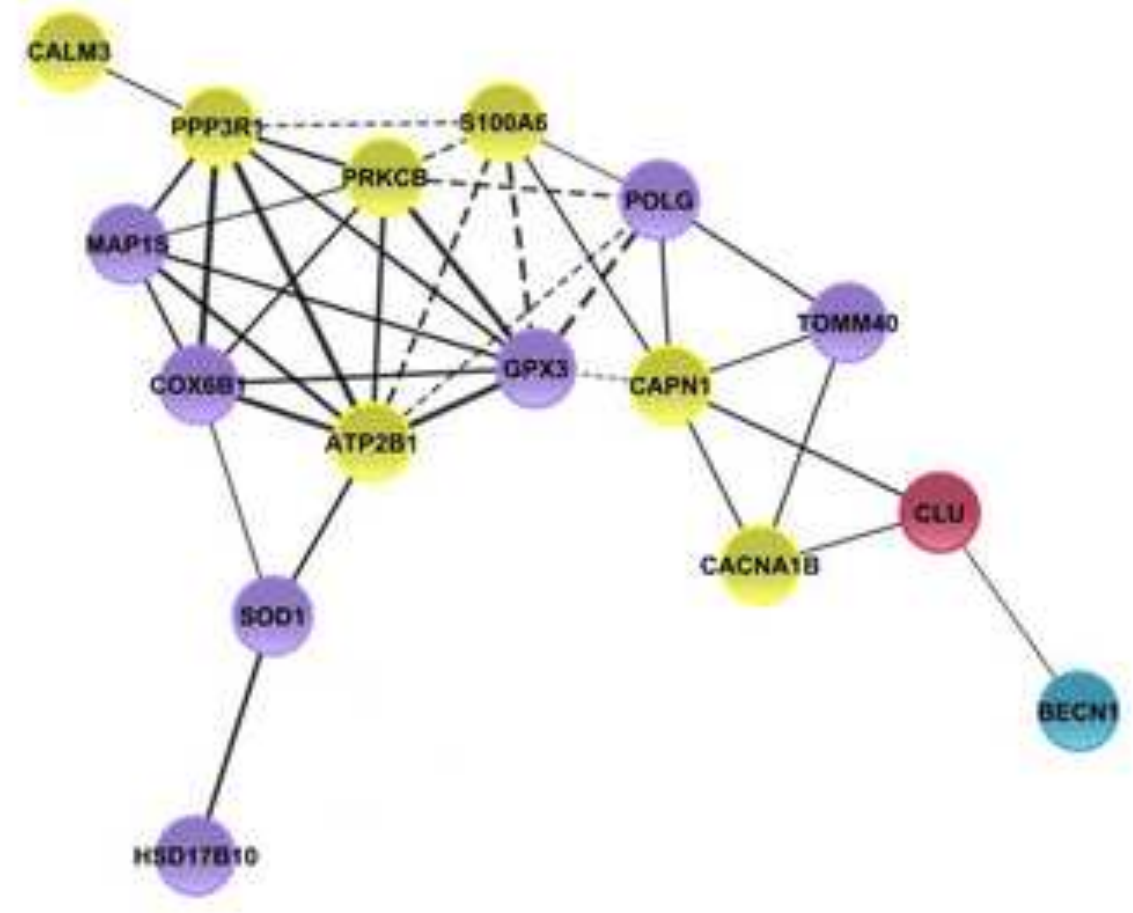

B)

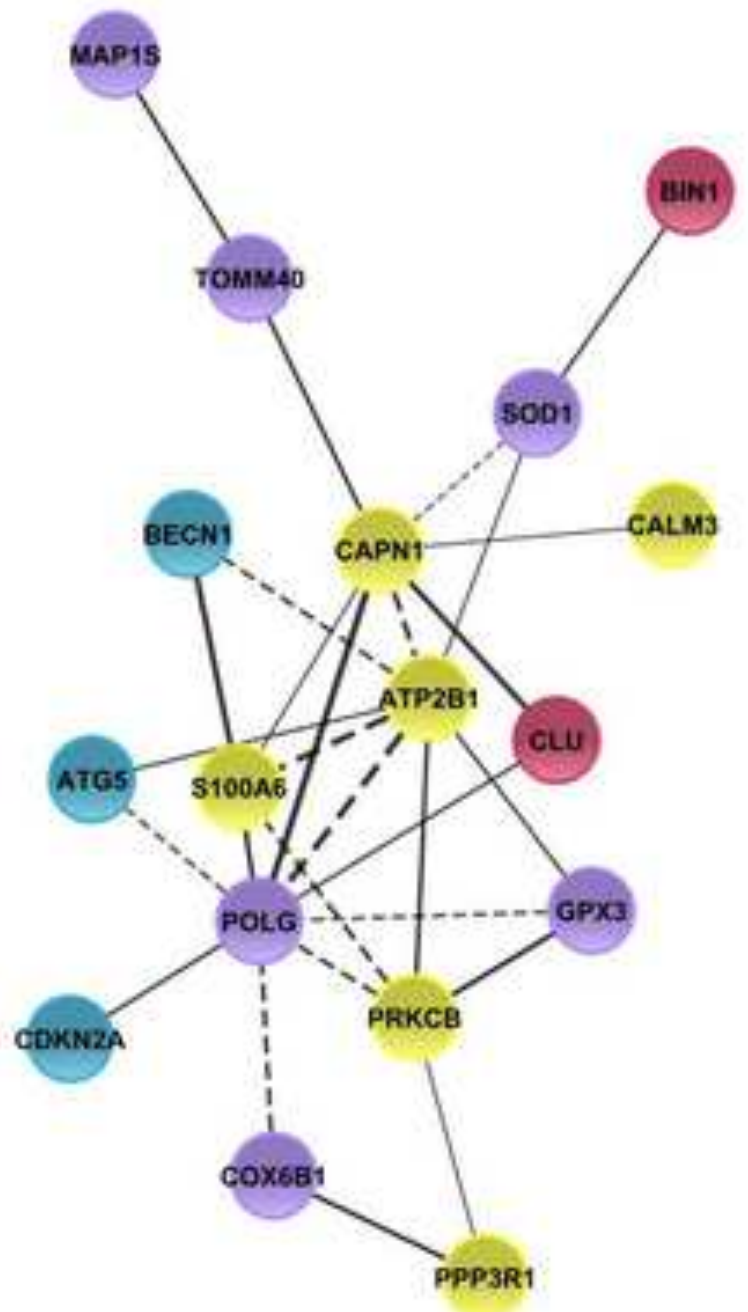

